\title{
Towards a Digital Museum Dream Space
}

\author{
Sarah Younan \\ Cardiff School of Art and Design \\ Cardiff Metropolitan University, Llandaff Campus, Cardiff, CF52YB, UK \\ sayounan@cardiffmet.ac.uk
}

\section{INTRODUCTION}

Digital three-dimensional (3D) scanning, editing and print technologies are giving rise to a number of unprecedented digital museum engagement practices, both fostered by museums and emerging outside the scope of these institutions. This paper examines how the creative engagement with digital 3D models of museum objects can link to the museum 'dream space' and reveal new possibilities in museums.

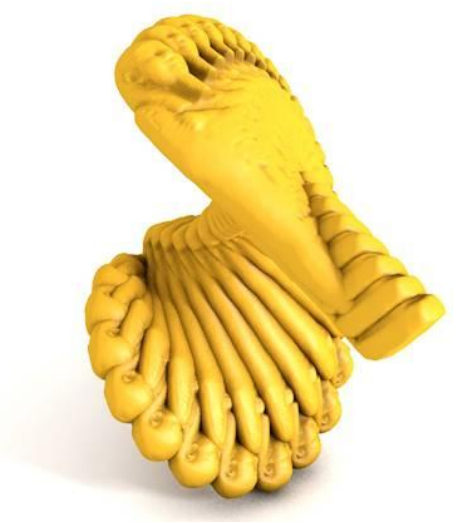

Figure 1: WsB Transforma, Mohammed Hossam, made using digital 3D model of museum artefact

\section{DIGITAL 3D MODELS}

The emergence of inexpensive and flexible 3D digitization tools and technologies and of increasingly easy to use and intuitive 3D editing software, as well as affordable and accessible 3D printing, has lowered the bar for creative engagement with the museum through digital 3D activities. Museums are increasingly making 3D models from their collections available online and a vast number of $3 \mathrm{D}$ digital models of museum

\footnotetext{
${ }^{1}$ See for example the Petrie museum's 3D website, http://www.ucl.ac.uk/3dpetriemuseum (retrieved 21 February 2015).
}

artefacts can be found on file sharing websites ${ }^{2}$, where they are added as user generated content (UCG). 3D scanning of physical artefacts translates the form of physical objects into digital models with a new set of contexts and meanings. 'Models of museum objects can take on a creative life of their own through further derivation' (Neely \& Langer 2013; see also Lovejoy 2004). Digital 3d models can be edited, animated and rendered into new creative works.

\subsection{Dream space}

The encounter with museum artefacts can be informative and instructive, but it can also give rise to subrational thought and emotions, and can trigger the recollection of memories (Annis 1986, Kavanagh 2000). Annis terms this field of museum engagement the museum 'dream space'.

Digital 3D models of museum artefacts closely resemble the original museum artefacts. However, while original museum artefacts rest within the museum, digital 3D models can cross the threshold into the private sphere of individuals. They permit transformation, experimentation and play. Through 3D editing private thoughts, emotions and memories can be expressed and new cultural artefacts emerge, which engage with the museum dream space.

We make meaning of the past through an active and ongoing dynamic. Popular culture and the mass media feed into our historical imagination (Wallace 1995). Museums can feed historical artefacts from their collections into this arena in the form of digital 3D models. Creative re-use of digital 3D models from museums can lead new audiences to engage with museums and to discover museum collections as sources of inspiration and creative content.

\footnotetext{
2 For example Thingiverse, see http://www.thingiverse.com/thing:25369 (retrieved 21 February 2015).
} 


\subsection{Digital visual literacy}

However, digital 3D models can be seen as a threat to museum's collections of authentic artefacts. Benjamin (1973) foresaw a depletion of the 'aura' of original objects through their automated reproduction and distribution. Baudrillard (1996) suggested that the shift from real objects to simulations would result in a loss of reality and lead to subsequent compensation through 'hyper reality'. This view identifies digital $3 \mathrm{D}$ models as a threat to museum culture and practise, 'based on a fear that as $3 \mathrm{D}$ simulations become more convincing, surrogates will merge in 'form' and affectual tome (...) with the physical object' (Eco 1990:51). However 'multiplication of an icon, far from diluting its cultic power, rather increases its fame' (Cameron, 2007:38). Distribution of copies, reproductions and images of an artwork can lead to increased awareness and interest in the original item itself.

At the same time, the creative use of digital 3D models from museums risks taking the $3 \mathrm{D}$ forms out of context. It can reduce their likeness to the original museum artefacts and can mislead viewers. They can be altered without leaving traces of manipulation; therefore viewers need to be 'more critical of visual material than in the past' (van Dam \& Spalter 2008:95). Digital visual materials (DVM) are now ubiquitous in our everyday lives. The digital visual literacy necessary to critically engage with DVM can be learnt through creative engagement with and exposure to DVM.

\section{CONCLUSION}

Museums willing to make digital 3D models of their collections available for creative use face many hurdles and challenges, financial as well as legal, organisational and technical. However, museums can collaborate with target audiences and take steps to foster digital creative engagement with their collections without investing a large amount of resources ${ }^{3}$.

The engagement and creative use of digital reproductions of museum artefacts can engage with the museum dream space and deal with the subjects of memory, culture and identity. While the creative use of digital reproductions of museum artefacts raises questions on authenticity and content there is no evidence to suggest they impact negatively on understandings of the original museum artefacts. Furthermore they can provide a

\footnotetext{
${ }^{3}$ The Metropolitan Museum in New York, for example, has published a how-to guide. See http://www.metmuseum.org/ /media/Files/Blogs/Digital\% 20Media/3DPrintingBookletforBeginners.pdf (retrieved 11 March 2015).
}

way for users and viewers to engage with museum collections, to gain digital visual literacy and to create and share new cultural content that pays homage to the past and connects it to the present.

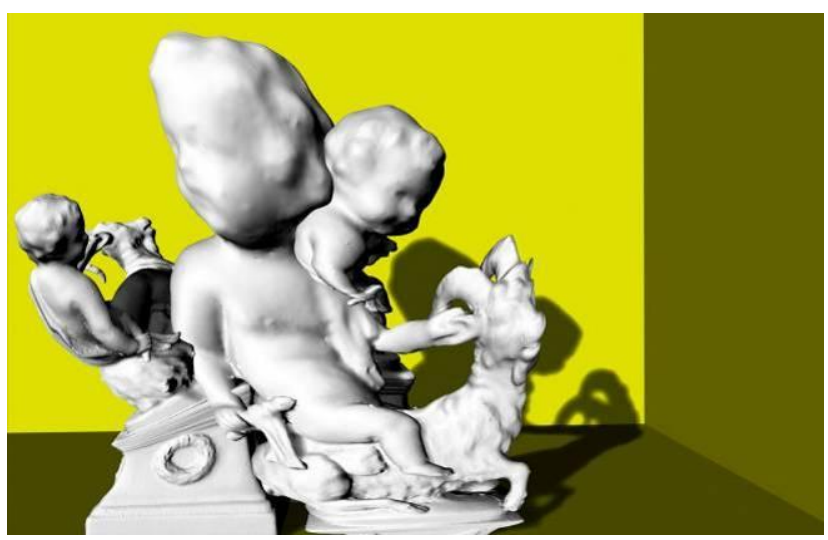

Figure 2: Interlude, John Rainey, still from animated film made using digital 3D model of museum artefact

\section{REFERENCES}

Annis, S. (1986) The Museum as Staging Ground for Symbolic Action. Museum International, 38, 168-171.

Baudrillard, J. (1996) The System of Objects, trans. Benedict, J., Verso, London/New York.

Benjamin, W. (1973) Illuminations, trans. H. Zohn. Fontana, London.

Cameron, F. (2007) Beyond the Cult of the Replicant. In F. Cameron \& S. Kenderdine (eds.), Theorizing Digital Cultural Heritage: A Critical Discourse. MIT Press, Massachusetts/London.

Kavanagh, G. (2000) Dream Spaces: Memory and the Museum, Bloomsbury, London.

Lovejoy, M. (2004) Digital Currents: Art in the Electronic Age, Routledge, New York.

Neely, L. and Langer, M. (2013) http://mw2013.museumsandtheweb.com/paper/ple ase-feel-the-museum-the-emergence-of-3dprinting-and-scanning/ (retrieved 21 February 2015).

Umberto, E. (1990) Travels in Hyper Reality, trans. W. Weaver. Harcourt Brace \& Company, Orlando/Florida.

van Dam, A. \& Spalter, S. (2008) Digital Visual Literacy, Theory Into Practice, 47(2), 93-101

Wallace, M. (1995) Changing media, changing messages. E. Hooper-Greenhill (ed.), Museum, Media, Message. Routledge, London. 